OPEN ACCESS

Edited by:

Edvaldo Antonio Ribeiro Rosa, Pontifícia Universidade Católica do

Paraná, Brazil

Reviewed by:

Taissa Vila,

University of Maryland, Baltimore,

United States

Sudhanshu Shukla,

Amity University, Gurgaon, India

*Correspondence:

Cristiane Y. Koga-Ito

cristiane@ict.unesp.br

Specialty section:

This article was submitted to

Antimicrobials, Resistance

and Chemotherapy,

a section of the journal

Frontiers in Microbiology

Received: 25 September 2017

Accepted: 20 March 2018

Published: 05 April 2018

Citation:

Teodoro GR, Gontijo AVL,

Salvador MJ, Tanaka MH,

Brighenti FL, Delbem ACB,

Delbem ÁCB and Koga-lto CY (2018)

Effects of Acetone Fraction From

Buchenavia tomentosa Aqueous

Extract and Gallic Acid on Candida

albicans Biofilms and Virulence

Factors. Front. Microbiol. 9:647.

doi: 10.3389/fmicb.2018.00647

\section{Effects of Acetone Fraction From Buchenavia tomentosa Aqueous Extract and Gallic Acid on Candida albicans Biofilms and Virulence Factors}

Guilherme R. Teodoro', Aline V. L. Gontijo ${ }^{1,2}$, Marcos J. Salvador'2, Márcia H. Tanaka1, Fernanda L. Brighenti ${ }^{3}$, Alberto C. B. Delbem ${ }^{4}$, Ádina C. B. Delbem ${ }^{4}$ and Cristiane Y. Koga-Ito ${ }^{1 *}$

'Environmental Engineering Department and Oral Biopathology Graduate Program, Institute of Science and Technology of São José dos Campos, São Paulo State University, São Paulo, Brazil, ${ }^{2}$ Department of Plant Biology, PPGBTPB, Institute of Biology, University of Campinas, Campinas, Brazil, ${ }^{3}$ Araquara Faculty of Dentistry, São Paulo State University, São Paulo, Brazil, ${ }^{4}$ Araçatuba Faculty of Dentistry, São Paulo State University, São Paulo, Brazil

A promising anti-Candida activity of Buchenavia tomentosa extracts was recently described. In the present work, experiments were carried out to determine the fraction with higher antifungal activity from a B. tomentosa extract. Acetone fraction (AF) was obtained from the aqueous extract from dried leaves $\left(5 \mathrm{~min} / 100^{\circ} \mathrm{C}\right)$ and it was the most effective one. Gallic acid (GA) was identified by electrospray ionization mass spectrometry (ESI-MS) and also chosen to perform antifungal tests due to its promising activity on Candida albicans. Minimal inhibitory and fungicidal concentrations (MIC and MFC) were determined by broth microdilution technique. The effect on virulence factors of $C$. albicans was evaluated, and the cytotoxicity was determined. $\mathrm{MIC}_{50}$ and $\mathrm{MIC}_{90}$ values were both equal to $0.625 \mathrm{mg} \mathrm{ml}^{-1}$ for $\mathrm{AF}$ and 2.5 and $5 \mathrm{mg} \mathrm{ml}^{-1}$, respectively, for GA. AF and GA showed ability to inhibit $C$. albicans adherence and to disrupt $48 \mathrm{~h}$-biofilm. AF and GA were effective in reducing the formation of hyphae of C. albicans SC5314. AF and GA decreased adherence of $C$. albicans to oral epithelial cells. AF and GA showed slight to moderate toxicity to Vero cells. This result suggests further studies for topic use of these compounds. AF, which contains a combination of several molecules, presented greater potential of antimicrobial activity than GA, with lower values of MIC and lower cytoxicity.

Keywords: phytotherapy, antifungal, Candida albicans, Buchenavia tomentosa, gallic acid, virulence factors

\section{INTRODUCTION}

Candida belongs to a vast and heterogeneous genus, presenting more than 200 species (Williams et al., 2013). The genus Candida presents many species, however only 20 are usually related to human infections (Williams et al., 2013), which range from superficial to systemic diseases. Superficial infectious, although less harmful, are more frequent and can be recurrent for some 
patients. Systemic infections initiate when fungi invade the epithelial barrier and reach the blood circulation, causing candidemia (Gow et al., 2012). The attributable mortality rate $(25-60 \%)$ of patients with candidemia varies from 25 to $60 \%$, with significant higher rates among developing countries (Kaur and Chakrabarti, 2017). Candida albicans is usually the most frequently involved species in cases of candidemia (Arendrup, 2013; da Matta et al., 2017; Fu et al., 2017).

Candida albicans expresses some virulence factors, which are important to initiate and establish the infectious process. The ability to form biofilms is one of its major virulence factors (Uppuluri et al., 2009). Biofilms are defined as a community of cells attached to a biotic or abiotic surface and covered by a polymer matrix (Donlan and Costerton, 2002). Such matrix protects the fungal cells from antimicrobial drugs, which makes biofilms very difficult to treat. There are two usual ways to treat biofilms. The first one is preventing the biofilm formation, avoiding its adherence or maturation (Girardot and Imbert, 2016). The second consists in the eradication of biofilm (Girardot and Imbert, 2016). Ideally, a good candidate to treat Candida biofilms should present both mechanisms.

Another virulence factor of $C$. albicans is the ability of changing from yeast cells to hyphae (Gow et al., 2012). This is a crucial step for the invasion of the epithelial barrier. The hyphal morphologies are believed to induce more tissue damage than yeast cells by producing and secreting lytic enzymes, such as secreted aspartyl proteinases (SAPs) (Naglik et al., 2003; Dalle et al., 2010).

Traditional antifungal drugs, such as azoles, amphotericin $B$, and echinocandin are generally used for the treatment of candidiasis (Pappas et al., 2004). Nonetheless, due to the limited number of antifungal agents and the misuse of the few available drugs, there are many cases of resistance among Candida species (Pappas et al., 2004). Natural products for the treatment of infections are promising, since they present lower toxicity with significant antimicrobial activity (Abreu et al., 2013).

Buchenavia tomentosa is a natural plant from the central region of Brazil which showed promising antifungal activity (Teodoro et al., 2015a; Brighenti et al., 2017). Although it is frequently used in the traditional medicine, there are only few studies in the scientific literature about the pharmaceutical applications of this plant.

In this context, the aims of this work were (i) to obtain different fractions of $B$. tomentosa leaves extracts and investigate their antifungal activity, (ii) to perform the chemical characterization of the most active fraction, (iii) to determine minimal inhibitory and fungicidal concentrations of this fraction, (iv) select one isolate compound with promising anti-candidal activity and determine inhibitory and fungicidal concentrations, and (v) to evaluate the effect of these antifungal agents on C. albicans virulence factors, determining their effect on biofilm formation and eradication, on the production of proteinase and phospholipase, on morphogenesis (hypha formation), and finally the in vitro activity on $C$. albicans adherence to oral epithelial cells.

\section{MATERIALS AND METHODS}

\section{Obtaining the Different Fractions From Aqueous Extracts of Buchenavia tomentosa Leaves}

The powdered, air-dried leaves of $B$. tomentosa (Teodoro et al., 2015a) (20 g) were extracted by maceration at $100^{\circ} \mathrm{C}$ for $5 \mathrm{~min}$ with $400 \mathrm{~mL}$ water (Salvador et al., 2006). The aqueous extract was concentrated under vacuum in a rotary evaporator and was suspended in methanol (1:5 $\mathrm{v} / \mathrm{v})$. Then, the resulted suspension was partionated with hexane $(1: 1 \mathrm{v} / \mathrm{v})$ and the corresponding hexanic fraction was removed before the addition of dichloromethane. Subsequently, the dichloromethane fraction was removed and the acetone solvent $(1: 1 \mathrm{v} / \mathrm{v})$ was added. Finally, the acetone fraction (AF) was obtained. The fractions were dried and resuspended in aqueous solution. A flow chart with the process of obtaining of the different fractions is available in (Supplementary Figure S1).

\section{Screening of the Antifungal Activity of the Fractions}

The methodology used for in vitro screening of the antifungal activity of the fractions was the double-layer agar technique. Reference strains of C. albicans (ATCC 18804 and SC 5314) were used. All four fractions obtained from the aqueous extract of $B$. tomentosa leaves were studied. The preparation of the substances and microorganisms was carried out as previously described (Teodoro et al., 2015a), with final concentration of the substances equal to $10 \mathrm{mg} \mathrm{mL} \mathrm{m}^{-1}$. Standardized fungal suspensions containing $10^{6}$ cells $\mathrm{ml}^{-1}$ were prepared and inoculated in RPMI 1640 agar. All the substances, except the AF, had 5\% DMSO added.

\section{Chemical Characterization of Acetone Fraction (AF) From B. tomentosa Aqueous Extract}

The characterization of the AF constituents was obtained by electrospray ionization mass spectrometry (ESI-MS) (Schinor et al., 2006). The samples were diluted in a solution containing $50 \% \quad(\mathrm{v} / \mathrm{v})$ chromatographic grade methanol, $50 \%(\mathrm{v} / \mathrm{v})$ of a deionized water solution and 0.5\% ammonium hydroxide (Merck, Darmstadt, Germany). The ESI-MS analyses were performed by direct injection in the Micromass ${ }^{\circledR}$ quadrupole mass spectrometer (Waters Corporation, Milford, MA, United States), by electro-spray in negative and positive mode as previously described (Teodoro et al., 2015a). The constituents were identified by comparison of ESI-MS/MS spectra results with the authentic standard sample spectrum from the Laboratory of Pharmacognosy, Phytopharmaceutical Technology and 
Bioassays of IB-Unicamp, as well as with data from the literature.

\section{Determination of Minimum Inhibitory Concentration and Minimum Fungicidal Concentration of the Acetone Fraction (AF) and Gallic Acid (GA)}

The reference strains C. albicans SC 5314 and ATCC 18804 were used, together with 27 previously obtained C. albicans clinical isolates from lesions of denture-associated erythematous candidiasis. The use of such strains was approved by the Local Human Research Ethics Committee (process \# 367.923). The broth microdilution technique was performed as previously described (Teodoro et al., 2015a). Fungal suspensions containing $10^{6}$ cells $\mathrm{ml}^{-1}$ were prepared with the aid of a spectrophotometer. The initial concentration of AF and GA was transferred to 96-well plates and then was twofold serial diluted in 1640 RPMI broth (without sodium bicarbonate, with L-alanine, supplemented with $2 \%$ glucose and buffered in $\mathrm{pH} 6.5$ with MOPS) to obtain a range of concentrations from 5 to $0.001 \mathrm{mg} \mathrm{mL}^{-1}$. After $24 \mathrm{~h}$ of incubation at $37^{\circ} \mathrm{C}$, under aerobiosis, the results were determined by visual reading compared to the negative control. Amphotericin B $\left(2 \mu \mathrm{g} \mathrm{mL}^{-1}\right)$ was used as the positive control. Three independent experiments were performed in triplicate.

\section{Evaluation Against Virulence Factors of Candida albicans}

Effect of Subinhibitory Concentration on C. albicans Biofilm Formation

The effect of AF and GA on biofilm formation was evaluated according to Capoci et al. (2015). C. albicans ATCC 18804, C. albicans SC 5314 and 3 clinical isolates were grown in Sabouraud dextrose agar and incubated at $37^{\circ} \mathrm{C}$ for $24 \mathrm{~h}$. Standardized fungal suspensions containing $10^{7}$ cells $\mathrm{ml}^{-1}$ were obtained spectrophotometrically. In order to evaluate the effect of $\mathrm{AF}$ and GA on biofilm formation, $20 \mu \mathrm{l}$ of fungal suspension was added to $180 \mu \mathrm{l}$ of RPMI (final concentration of $10^{6} \mathrm{cells} \mathrm{ml}^{-1}$ ) with $2 \%$ glucose supplemented with AF and GA at subinhibitory concentrations $\left(\mathrm{AF}=1.25 \mathrm{mg} \mathrm{ml}^{-1}\right.$ and $\left.\mathrm{GA}=2.5 \mathrm{mg} \mathrm{ml}^{-1}\right)$. The plates were incubated at $37^{\circ} \mathrm{C}$ under agitation $(80 \mathrm{rpm})$ for 24 and $48 \mathrm{~h}$. After this period, the biofilms were disrupted by vigorous vortexing followed by sonication. The suspensions were plated on Sabouraud dextrose agar. The plates were incubated at $37^{\circ} \mathrm{C}$ for $24 \mathrm{~h}$ and the number of colony forming units (CFUs) was obtained.

\section{Effect on Preformed Biofilm}

The methodology to evaluate the effect of AF and GA on pre-formed biofilm was based on Cheng et al. (2011), with some modifications. For this step, strains of $C$. albicans ATCC 18804, C. albicans SC 5314 and 3 clinical isolates were used. The 24 and $48 \mathrm{~h}$ biofilms were formed in polystyrene test specimens $\left(50 \mathrm{~mm}^{2}\right)$, previously sterilized by UV radiation for $30 \mathrm{~min}$. The inoculums containing $10^{7}$ cells $/ \mathrm{ml}$ were prepared with the aid of a spectrophotometer, as previously described (Teodoro et al., 2015a). $20 \mu \mathrm{l}$ of the inoculums were then added to $180 \mu \mathrm{l}$ of RPMI with $2 \%$ glucose in 96-well plates.

All plates were incubated for $120 \mathrm{~min}$ at $37^{\circ} \mathrm{C}$ at $80 \mathrm{rpm}$ shaking for the pre-adhesion phase. The specimens were subsequently washed with $0.9 \% \mathrm{NaCl}$ and transferred to new 96-well plates with $200 \mu \mathrm{l}$ of RPMI with $2 \%$ glucose. After 24 or $48 \mathrm{~h}$, the formed biofilms were exposed to 2 and 4 times MIC of tested substances for $5 \mathrm{~min}$ at room temperature. After this contact, the specimens were again washed and transferred to tubes containing $1 \mathrm{~mL}$ of $0.9 \% \mathrm{NaCl}$ solution. The tubes were shaken for $60 \mathrm{~s}$ in vortex and also sonicated ( 2 pulses of $15 \mathrm{~s}$ with a $20 \mathrm{~s}$ interval, amplitude $40 \%$ and power of $15 \mathrm{~W}$ on ice) for biofilm disruption. The suspensions were plated on Sabouraud dextrose agar and incubated for $48 \mathrm{~h}$ at $37^{\circ} \mathrm{C}$ to obtain the values of CFUs/specimen.

\section{Effect on the Production of Proteinase and Phospholipase}

The formation of proteinase and phopholipase enzymes was evaluated in all the C. albicans strains described above (2 reference and 27 clinical isolates) after exposure to the tested substances. For this purpose, suspensions of $10^{6}$ cells $\mathrm{ml}^{-1}$ were prepared and exposed in aqueous solution of AF and GA at 1/2 MIC. The samples were incubated for $1 \mathrm{~h}$ at $37^{\circ} \mathrm{C}$ in $80 \mathrm{rpm}$ rotation. As a positive control, PBS was used. The verification of proteinase and phospholipase production was made pipetting an aliquot of $2 \mu \mathrm{L}$ of the treated strains into appropriate culture media.

The test medium for the evaluation of phospholipase production consisted of malt extract agar containing $1 \mathrm{M}$ sodium chloride, $0.005 \mathrm{M}$ calcium chloride and 2\% egg yolk (bacto egg yolk enrichment 50\%, $4 \mathrm{ml}$ in $100 \mathrm{ml}$ of agar) (Polak, 1992). For proteinase production assay, the test medium consisted of agar plates containing bovine serum albumin. $60 \mathrm{ml}$ of a solution containing $0.04 \mathrm{~g} \mathrm{MgSO}_{4} .7 \mathrm{H}_{2} \mathrm{O}, 0.5 \mathrm{~g} \mathrm{~K}_{2} \mathrm{HPO}_{4}, 1 \mathrm{~g} \mathrm{NaCl}, 0.2 \mathrm{~g}$ dried yeast extract, $4 \mathrm{~g}$ glucose, and $0.5 \mathrm{~g}$ BSA (fraction V) was prepared and the $\mathrm{pH}$ adjusted to 3.5 with $1 \mathrm{~N} \mathrm{HCl}$. This solution was sterilized by filtration and mixed with $140 \mathrm{ml}$ of melted agar. After 4 days of incubation at $37^{\circ} \mathrm{C}$, the enzymatic activity $(\mathrm{Pz})$ was measured in terms of the ratio of the diameter of colony plus zone of halo, according to previous studies (Aoki et al., 1990; Polak, 1992). The Pz values were transformed into scores: (1) when the enzymatic activity was negative $(\mathrm{Pz}=1)$, (2) when the activity was positive ( $\mathrm{Pz}$ between 0.99 and 0.7 ) and (3) when the activity was strongly positive $(\leq 0.69)$. The experiments were carried out in triplicate in three independent experiments.

\section{Effect on Morphogenesis (Hyphae Formation)}

The assays were performed according to Chevalier et al. (2012) with some modifications. Suspensions with $10^{5}$ cells $/ \mathrm{ml}$ of C. albicans reference strains (ATCC 18804 and SC 5314) were prepared in RPMI containing AF and GA at 1/2 MIC. The negative control was RPMI without the substances. An aliquot of $1 \mathrm{ml}$ of the preparations was transferred to 24 -well plates and incubated at $37^{\circ} \mathrm{C}$. Hyphae counts were performed using 
an optical microscope (200X) after 4 and 24 h of incubation at $37^{\circ} \mathrm{C}$, including both true hyphae and pseudohyphae. Tests were performed in triplicate in three independent experiments.

\section{In Vitro Effect on C. albicans Adherence to Oral Epithelial Cells}

The adherence of C. albicans to oral epithelial cells was performed according to Wellmer and Bernhardt (1997). The reference strains (ATCC 18804 and SC 5314) were plated on Sabouraud Dextrose agar and incubated at $37^{\circ} \mathrm{C}$ for $24 \mathrm{~h}$. After the incubation, the cells were centrifuged $(5000 \times g$ for $3 \mathrm{~min})$ and washed three times in $5 \mathrm{ml}$ PBS. A $10^{6}$ cells $\mathrm{ml}^{-1}$ suspension was obtained as previously described. C. albicans cells were exposed to $1 / 2 \mathrm{MIC}$ of AF and GA for $1 \mathrm{~min}$. Following this, the yeasts were again centrifuged and washed with PBS. Epithelial cells were obtained from healthy volunteers, after signing the informed consent form (Local Ethical Committee protocol \# 367.923), by scraping the jugal mucosa using sterile wooden spatulas. The obtained epithelial cells were centrifuged $(10000 \times g$ for $30 \mathrm{~s})$ and washed three times with PBS. A suspension containing $10^{5}$ cells $\mathrm{ml}^{-1}$ was obtained by counting in Neubauer's chamber. The aliquot of $100 \mu \mathrm{l}$ of C. albicans blastoconidia and $100 \mu \mathrm{l}$ of epithelial cell suspensions was mixed and incubated at $37^{\circ} \mathrm{C}$ for $1 \mathrm{~h}$. Negative control (without treatment) was included. The mixture was filtered using membranes of $12 \mu \mathrm{m}$ to eliminate the non-adhered C. albicans cells. Filters were washed with $0.5 \mathrm{ml}$ of PBS and the contents of this wash were stained with crystal violet. The number of yeasts adhered in 25 epithelial cells was quantified.

\section{Cytotoxicity Assay}

$6 \times 10^{4}$ Vero cells (fibroblast-like from kidney of green monkey) were seeded on 96-well plate and cultured under a temperature of $37^{\circ} \mathrm{C}$ and an atmosphere of $95 \%$ air and $5 \% \mathrm{CO}_{2}$. Tests were carried out according to the International Organization of Standardization [ISO] (2009) 10993-5. The cells were grown in a cell culture medium containing Dulbecco's modified Eagle's medium (DMEM) supplemented with $5 \%$ of inactivated fetal bovine serum, $100 \mathrm{IU} \mathrm{mL} \mathrm{mL}^{-1}$ of penicillin and $100 \mu \mathrm{g} \mathrm{mL}^{-1}$ of streptomycin and then incubated for $24 \mathrm{~h}$ to attach to the plate. AF and GA, at 0.625 and $1.25 \mathrm{mg} \mathrm{ml}^{-1}$, respectively, were incubated for $24 \mathrm{~h}$. A volume of $100 \mu \mathrm{L}$ of phosphate buffer solution (PBS) containing $0.5 \mathrm{mg} \mathrm{ml}^{-1} 3$-(4,5-Dimethylthiazol2-yl)-2,5-diphenyl tetrazolium bromide (MTT) was added and incubated for another $4 \mathrm{~h}$. MTT solution was replaced by DMSO in order to dissolve the formazan crystals. The values of MTTassay were measured using a microplate reader at $570 \mathrm{~nm}$ (Biotek Synergy $^{\text {TM }}$ HT, Winooski, VT, United States). Nontreated cells were used as negative control. The percentage of cell viability was obtained considering the negative control as $100 \%$. All the experiments were performed at least two times in triplicate.

\section{Statistical Analyses}

The statistical analysis was performed with GraphPad Software, Inc. (San Diego, CA, United States) and a minimal level of significance of $5 \%$ was considered. The non-parametric KruskalWallis or Friedman tests and Dunn's multiple comparison post hoc test were applied since the distribution of data was not normal according to the D'Agostino \& Pearson omnibus normality test.

\section{RESULTS}

\section{The Acetone Fraction Was the Most Promising Product}

Four types of fractions from $B$. tomentosa aqueous extract were obtained: acetone, hydroalcoholic, hexane, and dichloromethane. The inhibition halos for fractions varied between 9 and $11 \mathrm{~mm}$. The yield in relation to dried leaves was $13.2 \%$ for acetone, $0.7 \%$ for hydroalcoholic, $0.1 \%$ for hexane, and $0.04 \%$ for dichloromethane. The results showed that the most promising fraction was acetone, which presented the best yield. The AF was thus selected for further studies.

\section{Chemical Profile of the Acetone Fraction (AF)}

The analysis by ESI-MS (Figure 1) showed the presence of some phenols, such as gallic acid (GA), kaempferol, epicatechin, ellagic acid, vitexin, and corilagin. From the pool of substances found in B. tomentosa extracts, GA showed promising anti-candidal activity $^{12}$. For this reason, GA was selected as a molecule of reference in this study.

\section{Determination of Minimum Inhibitory Concentration and Minimum Fungicidal Concentration of the Acetone Fraction and Gallic Acid}

The MICs for all strains of C. albicans varied between 0.019 and $2.5 \mathrm{mg} \mathrm{ml}^{-1}$ for AF. The $\mathrm{MIC}_{50}$ and $\mathrm{MIC}_{90}$ values for AF, which are respectively the MIC for the 50 and $90 \%$ of the clinical strain samples, were both equal to $0.625 \mathrm{mg} \mathrm{ml}^{-1}$. The MIC values for GA varied from 0.625 to $5.0 \mathrm{mg} \mathrm{ml}^{-1}$ and $\mathrm{MIC}_{50}$ and $\mathrm{MIC}_{90}$ were 2.5 and $5 \mathrm{mg} \mathrm{ml}^{-1}$, respectively.

For the next tests, we have chosen the highest values of MIC for $\mathrm{AF}$ and $\mathrm{GA}$, which were 2.5 and $5.0 \mathrm{mg} \mathrm{ml}^{-1}$, respectively.

\section{Evaluation of the Effects on Virulence Factors of $\boldsymbol{C}$. albicans AF and GA Affect Biofilm Formation by C. albicans}

The results showed that the presence of AF and GA at $1 / 2$ MIC significantly reduced $(P<0.05)$ the adherence of $C$. albicans. Counts of viable cells in the biofilms were lower in biofilms treated for 24 and $48 \mathrm{~h}$ in comparison to the control (non-treated) (Figure 2).

\section{AF Disrupted 24 and 48-h Preformed Biofilms}

The ability of AF and GA to disrupt preformed biofilms of 24 and $48 \mathrm{~h}$ was then investigated and all the treatments reduced the viability of preformed biofilm in comparison to control, apart from GA 2X MIC (24 h) (Figure 3). For 24 h-biofilms, 


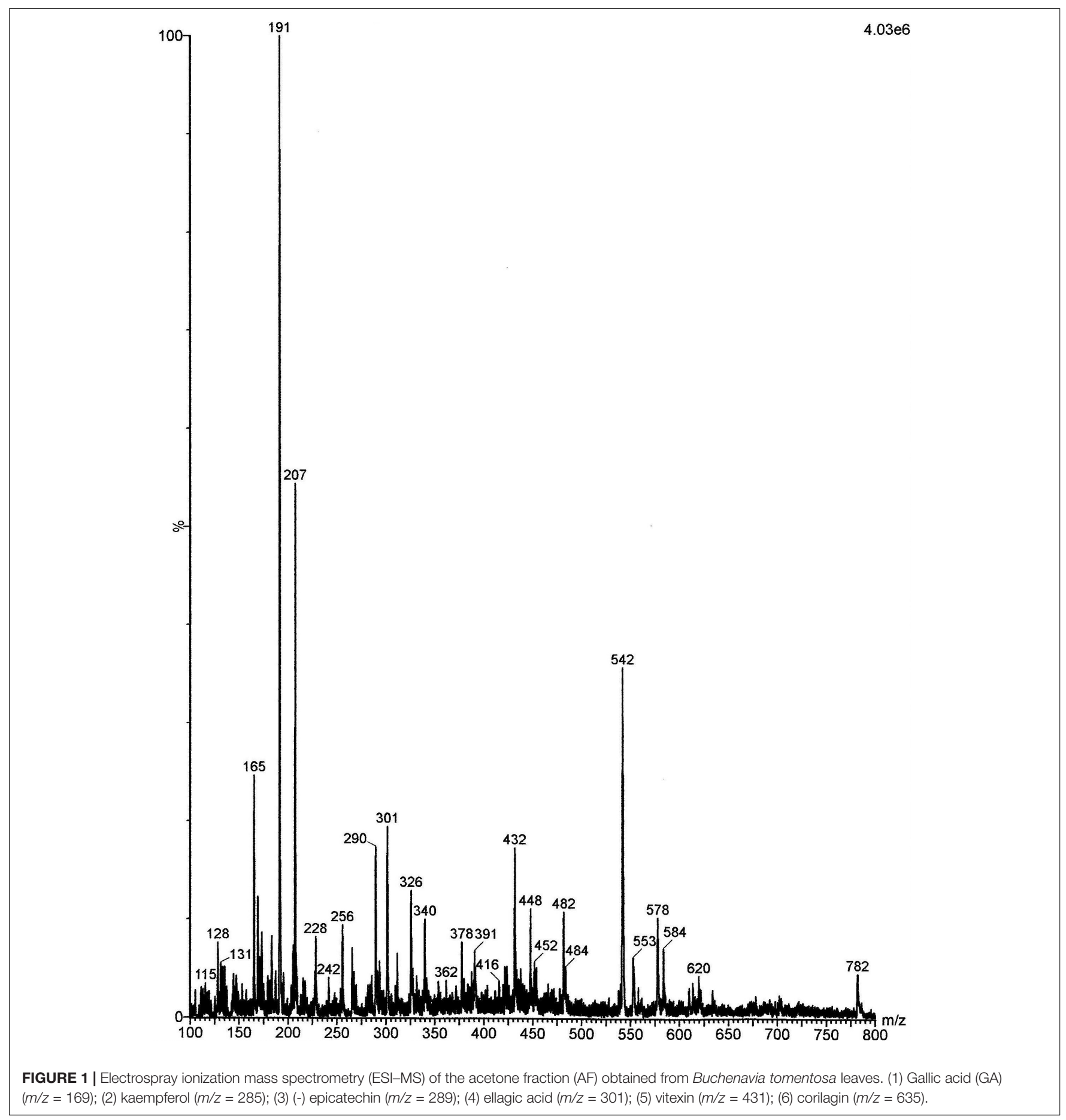

there was no statistical difference between 2 and 4X MIC of AF. It is important to notice that there was also no statistical difference between both AF concentrations and AmB, which is one of the reference molecules to treat infections caused by C. albicans. This points out to a promising antifungal activity of AF. For comparative purposes, all the data corresponding to GA $2 \mathrm{X}$ MIC and $\mathrm{AmB}\left(2 \mu \mathrm{g} \mathrm{ml}^{-1}\right)$ were extracted from another study performed by our group (Teodoro et al., 2017). It is important to highlight that all these experiments were performed simultaneously. GA 2X MIC was significantly different from AmB, with $P<0.001$.

For 48 h-biofilms, which can be considered as mature, $\mathrm{AF}$ was efficient in both concentrations and there was also no statistical difference between both ( 2 and $4 \mathrm{X}$ the MIC). These concentrations did not differ from the AmB treatment, reinforcing the potential of $\mathrm{AF}$ as an antifungal product. The 


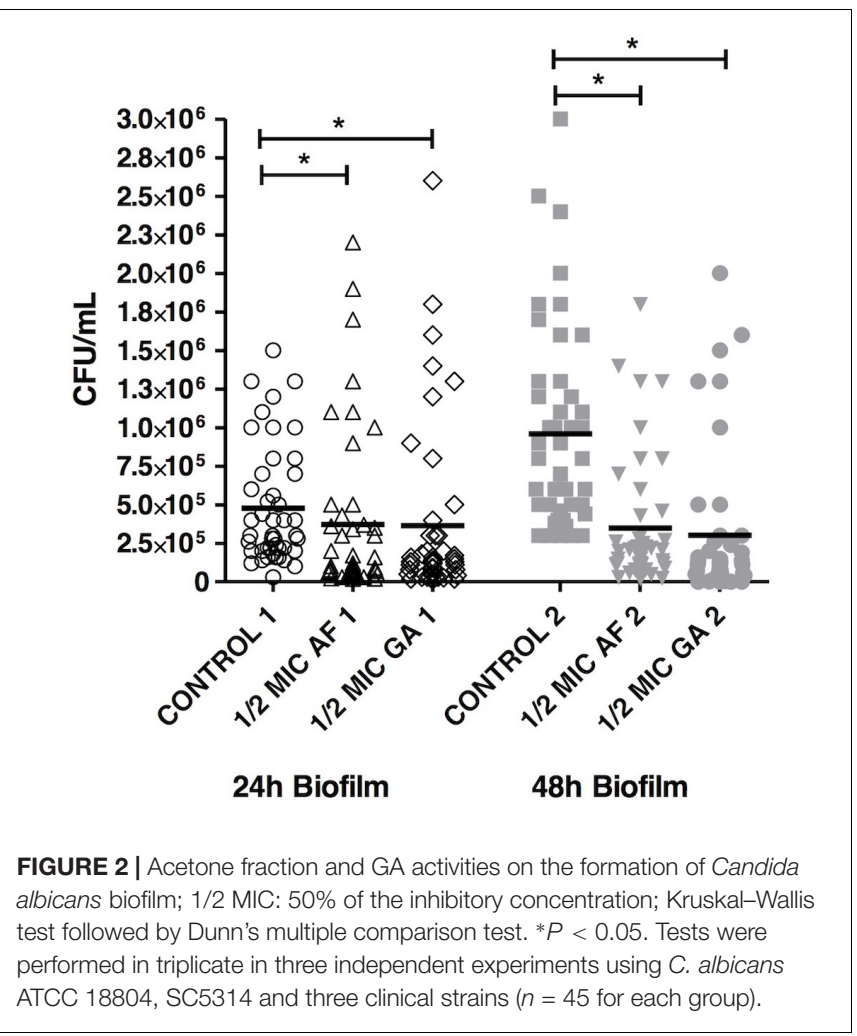

count of C. albicans was also reduced after the treatment with GA 2X MIC in comparison to the control group $(P<0.05)$.

\section{AF and GA Showed No Effect on C. albicans Enzymatic Activity}

The median value for the enzymatic activity $(\mathrm{Pz})$ of the proteinase was 0.45 for all groups (control, AF and GA), which means a strong positive enzymatic activity (score 3 ). Statistical analyses did not show a difference between the activity of proteinase for these groups ( $P>0.05$, Friedman/Dunn's test) (Figure 4A). The median values for the enzymatic activity $(\mathrm{Pz})$ of the phospholipase were $0.41,0.36$, and 0.39 (respectively for control, AF and GA), meaning that enzymatic activity was still strong for all groups (score 3$)$. Statistical analyses did not show a difference between the activity of phospolipase for these groups $(P>0.05$, Friedman/Dunn's test) (Figure 4B).

\section{AF and GA Inhibited C. albicans Adherence to Oral Epithelial Cells and Morphogenesis}

Treatments with both AF and GA were effective in reducing the formation of hyphae of C. albicans SC 5314 in comparison to the control (Figure 5). For the ATCC 18804 strain, the treatment with AF was able to reduce the formation of hyphae after 4 and $24 \mathrm{~h}$. After $4 \mathrm{~h}$, there was a small hyphae formation by ATCC 18804 that was not influenced by the treatment with GA $(P>0.05)$. GA was effective in reducing hyphae from ATCC 18804 only after $24 \mathrm{~h}$ (Figure 5).

Treatments with AF and GA decreased adherence of C. albicans strains ATCC 18804 and SC $5314(P<0.001)$ to oral epithelial cells (Figure 6).

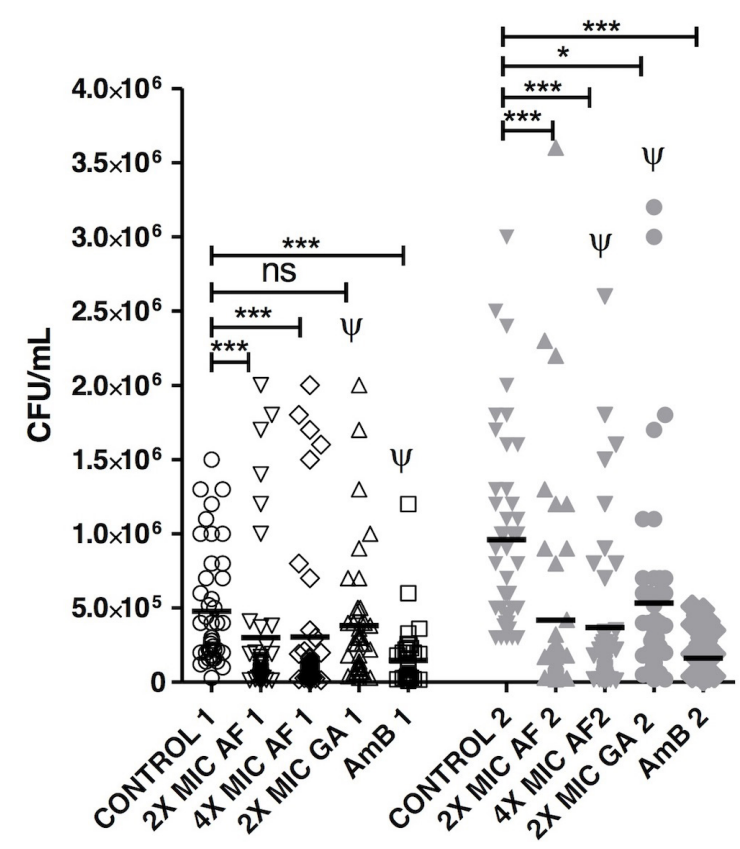

24h Biofilm

48h Biofilm

FIGURE 3 | Acetone fraction and GA activities on the eradication of C. albicans biofilm; 2 and $4 \mathrm{X}$ MIC: 2 and 4 times the minimum inhibitory concentration; AmB, amphotericin B at $2 \mu \mathrm{g} \mathrm{ml}^{-1}$; Kruskal-Wallis test followed by Dunn's multiple comparison test. ${ }^{*} P<0.05$, ${ }^{* * *} P<0.0001$; ns, not statistically significant. $\Psi$ : Data collected from Teodoro et al. (2017). Tests were performed in triplicate in three independent experiments using C. albicans ATCC 18804, SC5314 and three clinical strains ( $n=45$ for each group)
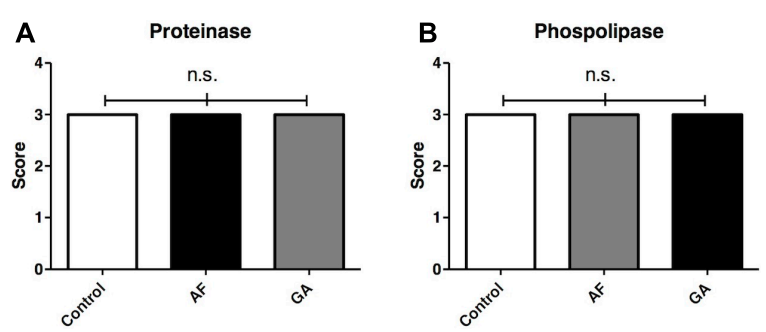

FIGURE 4 | Score representing the activity of control and treatment groups on the production of exoenzymes proteinase $\mathbf{( A )}$ and phospholipase $\mathbf{( B )}$ by C. albicans. AF and GA were tested at subinhibitory concentration (1/2 MIC). Dunn's multiple comparison test. Friedman test followed by Dunn's multiple comparison test; ns, not statistically significant. Tests were performed in triplicate in three independent experiments. Results are expressed as median.

\section{AF and GA Showed Slight to Moderate Cytoxicity}

The values of cell viability after $\mathrm{AF}$ treatment at $\mathrm{MIC}_{90}$ $\left(0.625 \mathrm{mg} \mathrm{ml}^{-1}\right.$ ), at $2.5 \mathrm{mg} \mathrm{ml}^{-1}$ (the highest value of MIC for $\mathrm{AF}$ ), at $5 \mathrm{mg} \mathrm{ml}^{-1}$ (2X MIC) and at $10 \mathrm{mg} \mathrm{ml}^{-1}$ (4X MIC) were, respectively, $70.5 \pm 6.3,58.9 \pm 15.2,45.0 \pm 10.9$, and $37.0 \pm 13.6 \%$ (Figure 7). For GA the cell viability at $1.25 \mathrm{mg} \mathrm{ml}^{-1}$ was $31 \pm 19 \%$. This result was obtained from Brighenti et al. (2017). 


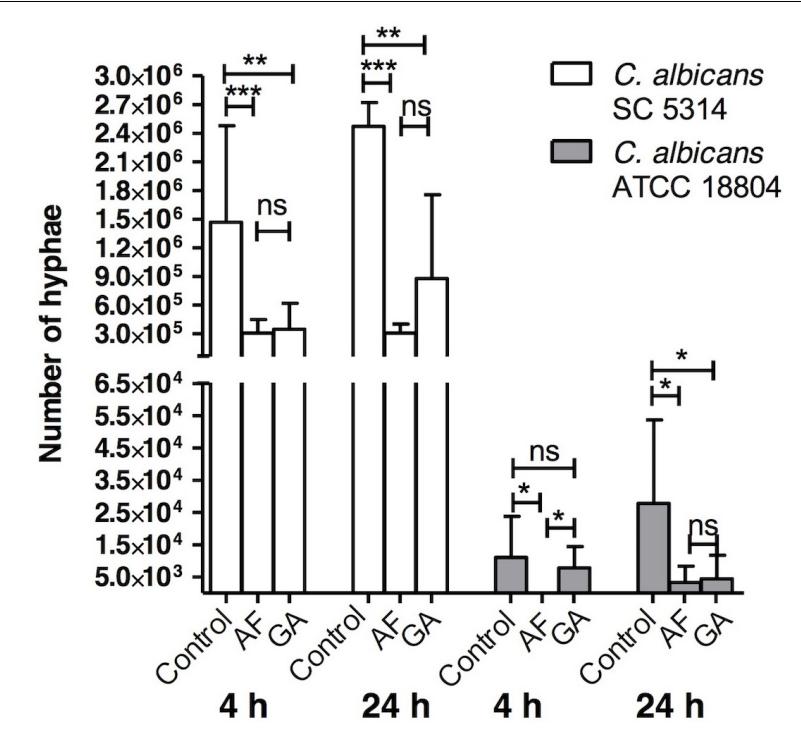

FIGURE 5 | Influence of AF and GA at subinhibitory concentration (half the minimum inhibitory concentration) in hyphae production by C. albicans ATCC 18804 and SC 5314; Kruskal-Wallis test followed by Dunn's multiple comparison test. ${ }^{*} P<0.05$; ${ }^{* *} P<0.001 ;{ }^{* * *} P<0.0001$; ns, not statistically significant. Tests were performed in triplicate in three independent experiments. Results are expressed as mean and SD, $n=9$ for each box.

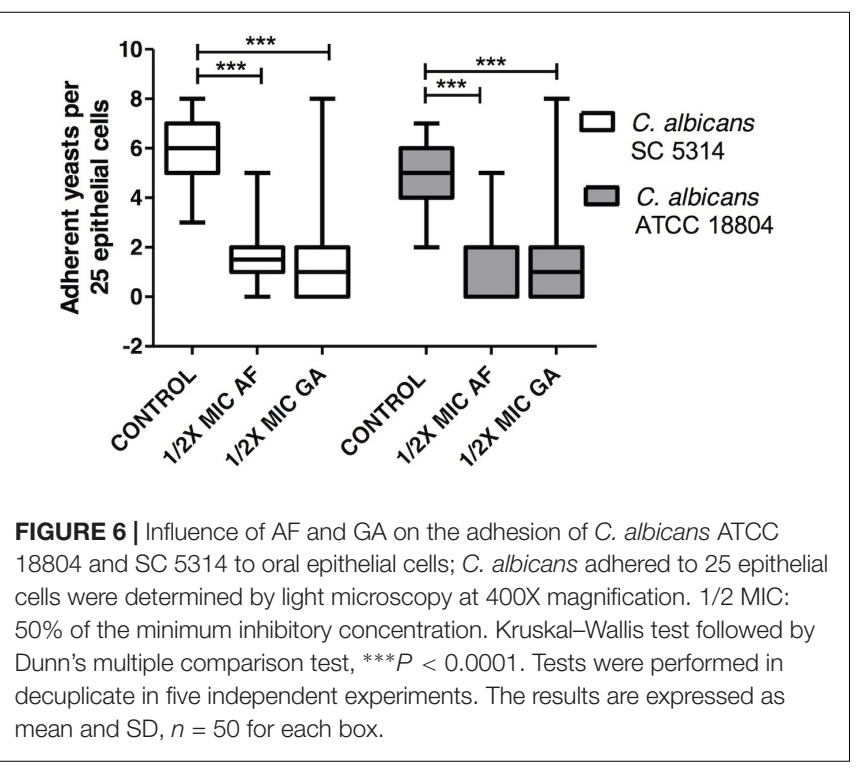

\section{DISCUSSION}

The AF from $B$. tomentosa aqueous extract presented antifungal activity on C. albicans. This fraction inhibited some C. albicans virulence factors, such as the ability to form biofilm, to change its morphology (from yeasts to hyphae), and to adhere to epithelial cells.

The analysis of AF by ESI-MS (Figure 1) showed a similar profile to the one obtained in previous works, which used aqueous (Teodoro et al., 2015a) and ethanolic extracts (Brighenti

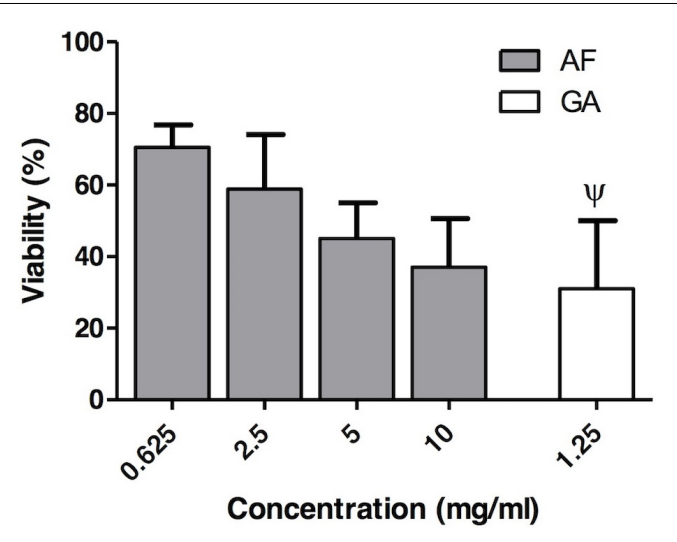

FIGURE 7 | In vitro cytotoxicity assay of the AF (gray boxes) at different concentrations $\left(0.625,2.5,5\right.$, and $10 \mathrm{mg} \mathrm{ml}^{-1}$ ) and GA (white box) $\left(1.25 \mathrm{mg} \mathrm{ml}^{-1}\right)$. Results are expressed as mean and SD, $n=6$ for each box. $\Psi$ : Data collected from Brighenti et al. (2017).

et al., 2017) from B. tomentosa. All these extracts showed the presence of some phenols, which are chemical compounds related to a potential antimicrobial activity (Teodoro et al., 2015b). In this present study, we performed the extraction with acetone, since this solvent can concentrate most efficiently the phenol content and thus increase the antimicrobial effect (Alberti et al., 2014).

It is interesting to notice that in previous studies the MICs for C. albicans ATCC 18804 of aqueous and ethanol $99^{\circ}$ extracts were, respectively, 12.5 (Teodoro et al., 2015a) and $0.4 \mathrm{mg} \mathrm{ml}^{-1}$ (Brighenti et al., 2017). In this present study, the MIC for C. albicans ATCC 18804 was much lower $\left(0.019 \mathrm{mg} \mathrm{ml}^{-1}\right)$, most probably due to the higher concentration of phenols present in $\mathrm{AF}$ compared to aqueous and ethanolic extracts. The extraction of phenols depends on the polarity of the solvent, as well as on the corresponding solubility of the compounds (Kchaou et al., 2013). In this present study, acetone seemed to have a more adequate polarity and solubility to extract higher amounts of phenol compounds than the other previously used solvents, such as water (Teodoro et al., 2015a) or ethanol $99^{\circ}$ (Brighenti et al., 2017).

Gallic acid was the phenol chosen in this study to investigate the antifungal activity as a molecule of reference of the AF fraction. It was selected due to its promising anti-candidal activity (Alves et al., 2014; Teodoro et al., 2015a). The mechanism of action of GA is not fully understood. Li et al. (2017) recently reported that GA reduced the activity of sterol 14 $\alpha$-demethylase P450 (CYP51), that is a cytochrome P450 enzyme involved in the biosynthesis of sterols (Hargrove et al., 2017). The values of MICs for $\mathrm{GA}$ are higher than the values for $\mathrm{AF}$, suggesting that $\mathrm{GA}$ is not the sole responsible for the antifungal activity of AF, which is mainly due to a synergism between the compounds present in this extract.

Acetone fraction and GA were able to inhibit the formation and to disrupt $C$. albicans biofilms (Figure 2). For GA, only one concentration (2X the MIC) was used, since $4 \mathrm{X}$ the MIC (i.e., $20 \mathrm{mg} \mathrm{ml}^{-1}$ ) is insoluble in water (Srinivas et al., 2010). A study performed by our group (Teodoro et al., 2017) improved the 
GA solubility using cyclodextrins, which increase the aqueous solubility. These molecules present a lipophilic cavity that hosts the water insoluble drug, and a hydrophilic exterior, which increases the aqueous solubility.

Surprisingly, GA at $2 \mathrm{X}$ MIC was able to reduce the 48 h-biofilm (Figure 2), without effect on the 24 h-biofilm. The authors previously hypothesized (Teodoro et al., 2017) that this phenomenon could be due to the dynamics of biofilm formation. In the biofilm of $24 \mathrm{~h}$, the composition of cells, molecular structures, and water are different from the biofilm of $48 \mathrm{~h}$, which could interfere on the efficiency of GA. Additionally, still according to Teodoro et al. (2017), GA might act on matrix compounds of biofilms, which are quantitatively more present in the $48 \mathrm{~h}$ biofilms.

Neither AF nor GA was able to reduce the proteinase and phospholipase productions by $C$. albicans, suggesting that these compounds are not able to act on these virulence factors of C. albicans. These results are in accordance with Li et al. (2001), which have shown that GA did not have an effect on the production of proteinases by C. albicans.

Acetone fraction and GA inhibited the formation of hyphae (Figure 5). Two reference strains of C. albicans were used in order to investigate the interspecies variability. As shown in Figure 5, and also in the literature (Hirakawa et al., 2015), SC5314 forms more hyphae than other strains. The inhibition of hyphae formation is an encouraging result, in particular considering the effect on a hyper filamentous strain (SC 5314). Filamentation is considered a crucial virulence factor in C. albicans ( $\mathrm{Lu}$ et al., 2014), as the hyphae form is related to increased tissue invasion of the host. Also, an attenuation of the in vivo virulence was observed as consequence of blocking filamentation (Saville et al., 2006). For this reason, substances or therapies targeting morphogenesis have been considered promising therapeutic options (Jacobsen et al., 2012).

Both treatments, AF and GA, decreased the adherence of C. albicans to oral epithelial cells. This finding is interesting since the adhesion on mucosal surfaces is a first step to start an infectious disease (Gow et al., 2012). There are some adhesins on the cell surface of $C$. albicans that bind to host surfaces. Hyphal wall protein 1 (Hwp1, encoded by the HWP1 gene) and the agglutinin-like sequence (ALS) family are widely studied adhesins and have been shown as important for the colonization by C. albicans in oral epithelial cells (Sundstrom et al., 2002). Further studies should be performed to investigate the AF and GA activity on these adhesins.

Acetone fraction $(70.5 \pm 6.3 \%)$ and GA $(31 \pm 19 \%)$ were, respectively, slightly and moderate cytotoxic according to Sletten and Dahl (1999) classification. For AF, even at the highest tested concentration $\left(10 \mathrm{mg} \mathrm{ml}^{-1}\right.$ ), the cytotoxicity was moderate (cell viability equal to $37.0 \pm 13.6 \%$ ), according to the aforementioned classification. For GA the cell viability was tested at $1.25 \mathrm{mg} \mathrm{ml}^{-1}$, which is lower than $\mathrm{MIC}_{90}\left(5 \mathrm{mg} \mathrm{ml}^{-1}\right)$. It was not possible to perform the cytotoxicity test with higher concentrations of GA, since above this concentration $\left(1.25 \mathrm{mg} \mathrm{ml}^{-1}\right)$ the GA reacts with the medium (DMEM) forming a dark coloration that biases the interpretation of results, since the methodology is colorimetric. Sletten and Dahl (1999) classified as severely toxic a compound presenting a cell viability lower than $30 \%$. Considering that the standard deviation is close to $20 \%$, GA is in the limit between moderately and severely toxic. It is important to emphasize that, in the present study, only one cell line was used (Vero cells). Future studies with other cell lines, such as keratinocytes, should be performed in order to validate the use of AF for treatment of superficial candidosis. These results reinforce that the AF, which contain a combination of several molecules, presents a greater potential of antimicrobial activity than its isolated molecule, the GA.

\section{CONCLUSION}

The AF presented the best antifungal activity among several extracts from $B$. tomentosa. Both AF and its isolated compound, the GA, presented activity on C. abicans; nonetheless, AF presented lower values of MIC and was less cytotoxic than GA. This study suggested that both, AF and GA, act on C. albicans reducing its virulence factors, such as ability to form biofilms, hyphae and to adhere on oral epithelial cells. Further studies using animal models are needed. The present work can contribute to the development of new products for the treatment of candidiasis.

\section{AUTHOR CONTRIBUTIONS}

GT, AG, MS, AD, ÁdD, FB, and CK-I designed the research. GT, AG, AD, ÁdD, MT, and FB performed the experiments. AG, MS MT, and CK-I analyzed the data. GT, AG, and CK-I wrote the paper. GT, AG, MS, MT, AD, ÁdD, FB, and CK-I critically revised the paper.

\section{FUNDING}

This work was supported by The São Paulo Research Foundation (FAPESP) Processes Nos. \#13/00037-1, \#12/16805-5, and \#14/09666-4.

\section{ACKNOWLEDGMENTS}

The authors thank The São Paulo Research Foundation (FAPESP) for the grant (\#2013/00037-1) and fellowships to GT (\#2012/16805-5) and AG (\#2014/09666-4). They also thank Clélia Aparecida de Paiva and Juliana Nóbrega Martins Marchesotti de Carvalho for their technical assistance.

\section{SUPPLEMENTARY MATERIAL}

The Supplementary Material for this article can be found online at: https://www.frontiersin.org/articles/10.3389/fmicb.2018. 00647/full\#supplementary-material

FIGURE S1 | Fractions obtained from aqueous extract from Buchenavia tomentosa. 


\section{REFERENCES}

Abreu, A. C., Malheiro, A. B. J., and Simões, M. (2013). "Resurgence of the interest in plants as sources of medicines and resistance-modifying agents," in Microbial Pathogens and Strategies for Combating them: Science, Technology and Education, ed. A. Méndez-Vilas (Badajoz: Formatex Research Center), 1287-1297.

Alberti, A., Zielinski, A. A. F., Zardo, D. M., Demiate, I. M., Nogueira, A., and Mafra, L. I. (2014). Optimisation of the extraction of phenolic compounds from apples using response surface methodology. Food Chem. 149, 151-158. doi: 10.1016/j.foodchem.2013.10.086

Alves, C. T., Ferreira, I. C., Barros, L., Silva, S., Azeredo, J., and Henriques, M. (2014). Antifungal activity of phenolic compounds identified in flowers from North Eastern Portugal against Candida species. Future Microbiol. 9, 139-146. doi: $10.2217 / \mathrm{fmb} .13 .147$

Aoki, S., Ito-Kuwa, S., Nakamura, Y., and Masuhara, T. (1990). Comparative pathogenicity of a wild-type strain and respiratory mutants of Candida albicans in mice. Zentralbl. Bakteriol. 273, 332-343. doi: 10.1016/S0934-8840(11) 80437-8

Arendrup, M. C. (2013). Candida and candidaemia. Susceptibility and epidemiology. Dan. Med. J. 60:B4698.

Brighenti, F. L., Salvador, M. J., Gontijo, A. V. L., Delbem, A. C. B., Delbem, Á. C. B., Soares, C. P., et al. (2017). Plant extracts: initial screening, identification of bioactive compounds and effect against Candida albicans biofilms. Future Microbiol. 12, 15-27. doi: 10.2217/fmb-2016-0094

Capoci, I. R. G., Bonfim-Mendonça, P. D. S., Arita, G. S., Pereira, R. R. D. A., Consolaro, M. E. L., Bruschi, M. L., et al. (2015). Propolis Is an Efficient Fungicide and Inhibitor of Biofilm Production by Vaginal Candida albicans. Evid. Based Complement. Alternat. Med. 2015:287693. doi: 10.1155/2015/ 287693

Cheng, L., Exterkate, R. A. M., Zhou, X., Li, J., and ten Cate, J. M. (2011). Effect of Galla chinensis on growth and metabolism of microcosm biofilms. Caries Res. 45, 87-92. doi: 10.1159/000324084

Chevalier, M., Medioni, E., and Precheur, I. (2012). Inhibition of Candida albicans yeast-hyphal transition and biofilm formation by Solidago virgaurea water extracts. J. Med. Microbiol. 61(Pt 7), 1016-1022. doi: 10.1099/jmm.0.041 699-0

da Matta, D. A., Souza, A. C. R., and Colombo, A. L. (2017). Revisiting species distribution and antifungal susceptibility of Candida bloodstream isolates from Latin American medical centers. J. Fungi 3:24. doi: 10.3390/jof302 0024

Dalle, F., Wächtler, B., L’Ollivier, C., Holland, G., Bannert, N., Wilson, D., et al. (2010). Cellular interactions of Candida albicans with human oral epithelial cells and enterocytes. Cell. Microbiol. 12, 248-271. doi: 10.1111/j.1462-5822. 2009.01394.x

Donlan, R. M., and Costerton, J. W. (2002). Biofilms: survival mechanisms of clinically relevant microorganisms. Clin. Microbiol. Rev. 15, 167-193. doi: 10.1128/CMR.15.2.167-193.2002

Fu, J., Ding, Y., Wei, B., Wang, L., Xu, S., Qin, P., et al. (2017). Epidemiology of Candida albicans and non-C. albicans of neonatal candidemia at a tertiary care hospital in western China. BMC Infect. Dis. 17:329. doi: 10.1186/s12879-0172423-8

Girardot, M., and Imbert, C. (2016). Novel strategies against Candida biofilms: interest of synthetic compounds. Future Microbiol. 11, 69-79. doi: 10.2217/fmb. 15.118

Gow, N. A., van de Veerdonk, F. L., Brown, A. J., and Netea, M. G. (2012). Candida albicans morphogenesis and host defence: discriminating invasion from colonization. Nat. Rev. Microbiol. 10, 112-122. doi: 10.1038/nrmicro 2711

Hargrove, T. Y., Friggeri, L., Wawrzak, Z., Qi, A., Hoekstra, W. J., Schotzinger, R. J., et al. (2017). Structural analyses of Candida albicans sterol $14 \alpha$-demethylase complexed with azole drugs address the molecular basis of azole-mediated inhibition of fungal sterol biosynthesis. J. Biol. Chem. 292, 6728-6743. doi: 10.1074/jbc.M117.778308

Hirakawa, M. P., Martinez, D. A., Sakthikumar, S., Anderson, M. Z., Berlin, A., Gujja, S., et al. (2015). Genetic and phenotypic intra-species variation in Candida albicans. Genome Res. 25, 413-425. doi: 10.1101/gr.174623.114
International Organization of Standardization [ISO] (2009). ISO 10993-5:2009. Biological Evaluation of Medical Devices - Part 5: Tests for in vitro cytotoxicity. Geneva: ISO.

Jacobsen, I. D., Wilson, D., Wächtler, B., Brunke, S., Naglik, J. R., and Hube, B. (2012). Candida albicans dimorphism as a therapeutic target. Exp. Rev. Anti Infect. Ther. 10, 85-93. doi: 10.1586/eri.11.152

Kaur, H., and Chakrabarti, A. (2017). Strategies to reduce mortality in adult and neonatal candidemia in developing countries. J. Fungi 3:41. doi: 10.3390/ jof3030041

Kchaou, W., Abbès, F., Blecker, C., Attia, H., and Besbes, S. (2013). Effects of extraction solvents on phenolic contents and antioxidant activities of Tunisian date varieties (Phoenix dactylifera L.). Ind. Crops Prod. 45, 262-269. doi: 10.1016/j.indcrop.2012.12.028

Li, X.-C., Jacob, M. R., Pasco, D. S., ElSohly, H. N., Nimrod, A. C., Walker, L. A., et al. (2001). Phenolic compounds from Miconia myriantha inhibiting Candida aspartic proteases. J. Nat. Prod. 64, 1282-1285. doi: 10.1021/np01 $0172 \mathrm{p}$

Li, Z.-J., Liu, M., Dawuti, G., Dou, Q., Ma, Y., Liu, H.-G., et al. (2017). Antifungal activity of gallic acid In Vitro and In Vivo. Phytother. Res. 31, 1039-1045. doi: $10.1002 /$ ptr.5823

Lu, Y., Su, C., and Liu, H. (2014). Candida albicans hyphal initiation and elongation. Trends Microbiol. 22, 707-714. doi: 10.1016/j.tim.2014. 09.001

Naglik, J. R., Challacombe, S. J., and Hube, B. (2003). Candida albicans secreted aspartyl proteinases in virulence and pathogenesis. Microbiol. Mol. Biol. Rev. 67, 400-428. doi: 10.1128/mmbr.67.3.400-428.2003

Pappas, P. G., Rex, J. H., Sobel, J. D., Filler, S. G., Dismukes, W. E., Walsh, T. J., et al. (2004). Guidelines for treatment of candidiasis. Clin. Infect. Dis. 38, 161-189. doi: $10.1086 / 380796$

Polak, A. (1992). Virulence of Candida albicans mutants. Mycoses 35, 9-16. doi: 10.1111/j.1439-0507.1992.tb00813.x

Salvador, M. J., Ferreira, E. O., Mertens-Talcott, S. U., De Castro, W. V., Butterweck, V., Derendorf, H., et al. (2006). Isolation and HPLC quantitative analysis of antioxidant flavonoids from Alternanthera tenella Colla. Z. Naturforsch. C. 61, 19-25. doi: 10.1515/znc-20061-204

Saville, S. P., Lazzell, A. L., Bryant, A. P., Fretzen, A., Monreal, A., Solberg, E. O., et al. (2006). Inhibition of filamentation can be used to treat disseminated candidiasis. Antimicrob. Agents Chemother. 50, 3312-3316. doi: 10.1128/AAC. 00628-06

Schinor, E. C., Salvador, M. J., Tomaz, J. C., Pral, E. M. F., Alfieri, S. C., Albuquerque, S. D., et al. (2006). Biological activities and chemical composition of crude extracts from Chresta exsucca. Rev. Bras. Ciênc. Farm. 42, 83-90. doi: 10.1590/S1516-93322006000100009

Sletten, G. B. G., and Dahl, J. E. (1999). Cytotoxic effects of extracts of compomers. Acta Odontol. 57, 316-322. doi: 10.1080/00016359942 8544

Srinivas, K., King, J. W., Howard, L. R., and Monrad, J. K. (2010). Solubility of gallic acid, catechin, and protocatechuic acid in subcritical water from (298.75 to 415.85) K. J. Chem. Eng. Data 55, 3101-3108. doi: 10.1021/je90 $1097 \mathrm{n}$

Sundstrom, P., Balish, E., and Allen, C. M. (2002). Essential role of the Candida albicans transglutaminase substrate, hyphal wall protein 1, in lethal oroesophageal candidiasis in immunodeficient mice. J. Infect. Dis. 185, 521-530. doi: $10.1086 / 338836$

Teodoro, G. R., Brighenti, F. L., Delbem, A. C. B., Delbem, A. C. B., Khouri, S., Gontijo, A. V. L., et al. (2015a). Antifungal activity of extracts and isolated compounds from Buchenavia tomentosa on Candida albicans and non-albicans. Future Microbiol. 10, 917-927. doi: 10.2217/fmb.15.20

Teodoro, G. R., Ellepola, K., Seneviratne, C. J., and Koga-Ito, C. Y. (2015b). Potential use of phenolic acids as anti-Candida agents: a review. Front. Microbiol. 6:1420. doi: 10.3389/fmicb.2015.01420

Teodoro, G. R., Gontijo, A. V. L., Borges, A. C., Tanaka, M. H., Lima, G. D. M. G., Salvador, M. J., et al. (2017). Gallic acid/hydroxypropyl- $\beta$-cyclodextrin complex: Improving solubility for application on in vitro/ in vivo Candida albicans biofilms. PLoS One 12:e0181199. doi: 10.1371/journal.pone.018 1199 
Uppuluri, P., Pierce, C. G., and López-Ribot, J. L. (2009). Candida albicans biofilm formation and its clinical consequences. Future Microbiol. 4, 1235-1237. doi: $10.2217 / \mathrm{fmb} .09 .85$

Wellmer, A., and Bernhardt, H. (1997). Adherence on buccal epithelial cells and germ tube formation in the continuous flow culture of clinical Candida albicans isolates. Mycoses 40, 363-368. doi: 10.1111/j.1439-0507.1997.tb0 0251.x

Williams, D. W., Jordan, R. P., Wei, X. Q., Alves, C. T., Wise, M. P., Wilson, M. J., et al. (2013). Interactions of with host epithelial surfaces. J. Oral Microbiol. 5:22434. doi: 10.3402/jom.v5i0. 22434
Conflict of Interest Statement: The authors declare that the research was conducted in the absence of any commercial or financial relationships that could be construed as a potential conflict of interest.

Copyright $\odot 2018$ Teodoro, Gontijo, Salvador, Tanaka, Brighenti, Delbem, Delbem and Koga-Ito. This is an open-access article distributed under the terms of the Creative Commons Attribution License (CC BY). The use, distribution or reproduction in other forums is permitted, provided the original author(s) and the copyright owner are credited and that the original publication in this journal is cited, in accordance with accepted academic practice. No use, distribution or reproduction is permitted which does not comply with these terms. 